\title{
The Spatio-Temporal Distribution of Malaria in Samfya District
}

\author{
Article by Cecilia K Muchepa Muzyamba \\ Education, Zambian Open University, Zambia \\ E-mail:ceciliamuchepa@yahoo.com
}

\begin{abstract}
Malaria was as old as human kind itself and had been the most potent scourge in humans from time immemorial in the World and Afro-Asian settings in particular. It was a disease caused by parasites of genus plasmodium namely: Plasmodium falciparum (Pf), Plasmodium ovale curtisi (Poc), Plasmodium ovale wallikeri (Pow), Plasmodium malariae (Pm), Plasmodium vivax (Pv) and Plasmodium Knowlesi (Pk) (Nzobo, Ngalasa and Kihamia 2015). These worked through a female anopheles mosquito. This study therefore, aimed to establish the spatio-temporal distribution of malaria in Samfya District, Zambia. Random and nonrandom research designs were used to obtain the sample and data for the study. There were 394 respondents, 3 Focus Group Discussions (FGDs) and 11 key informants.

The results showed that there were more women than men who were afflicted by malaria as evidenced in the questionnaires, FGDs and the hospital records. Age too was a contributing factor as the under 5 year old (U/5 years) and the aged were more vulnerable to malaria as their immunities were low due to nutrition deficiencies. Income determined whether a household could afford to buy an ITN or any mosquito sprays to control the mosquito nuisance. The population was poor as $72.2 \%$ of the respondents earned less than ZMK 700 (US \$ 70) per month. This was also related to the occupations the population was engaged in. Sixty-one point five percent (61.5\%) were farmers who earned their incomes once per year after their crop harvests.

House construction materials showed that $60 \%$ of the roofs were grass thatched, Iron/Asbestos (33.5\%) and tiles (2.3\%). The exterior house construction materials results were as follows: burnt bricks (61.2\%), cement blocks (13.7\%), unburnt bricks (10.9\%), timber (5.3\%) and straw/grass (0.3\%). In terms of sources of energy, there were 5 sources that were used by the respondents in the study and these were: hydroelectricity (9.4\%), Firewood (50.5\%), Charcoal (36.3\%), Crop residue (3\%) and Firewood and Charcoal $(0.8 \%)$.These factors contributed to the spatio-temporal distribution of malaria in Samfya District.
\end{abstract}

Keywords: Distribution, Malaria, Spatial, Temporal

\section{Introduction}

Malaria was made out of words and these were: 'mala' which meant 'bad' and 'aria' meant 'air'. It was an infectious disease that was caused by a parasite belonging to the genus plasmodium and was transmitted from one human being to another by a bite of infected anopheles mosquitoes (Patney 2013).Malaria was the biggest health problem facing many countries in the world (Nzobo et al. 2015) especially those found between latitudes 450 North and 450 South (Patney 2013:312). The disease therefore, was said to be found in the tropical and Sub-tropical areas (Snow and Omumbo 2006) because of their conducive climatic conditions. In these areas, rainfall was more than 80 millimetres $(80 \mathrm{~mm})$, temperature was in the range of $250 \mathrm{C}$ to $300 \mathrm{C}$ and humidity was more than $60 \%$ during the high malaria transmission season (Snow and Omumbo 2006). The endemicity malaria was therefore found in Africa, Asia, Central and South America, and Indonesia (World Health Organization [WHO] and United Nations International Children's Emergency Fund [UNICEF] 2005).

The most affected area in Africa is that which was found south of the Sahara where plasmodium falciparum parasite was very prevalent. In Zambia, malaria was endemic and 
stratified into three epidemiological zones namely: zone 1 which had malaria prevalence rate of less than 1\% (Lusaka and its environs); in zone 2, the malaria control and prevalence had remarkably reduced transmission and parasite prevalence to less than $10 \%$ (Central, Copperbelt, North-Western, Southern and Western Provinces); and zone 3 had the parasite prevalence exceeding 20\% during the transmission season (Eastern and Luapula Provinces) (Ministry of Health [MoH] 2014, 2013).

\section{Statement of the problem}

Malaria, with its debilitating effects was the leading cause of child and maternal (especially pregnant women) morbidity and mortality (Sonko et al. 2014). Ministry of Health (MoH 2010) argued that control of malaria in Luapula had been attained and lapses in prevention coverage had led to the resurgence of the infection and illness. This statement had implications in the spatio-temporal distribution of malaria in Luapula. This study therefore, aimed at establishing the spatio-temporal distribution of malaria in Samfya District.

\section{Objective}

The objective of this study was to establish the spatio-temporal distribution of malaria in Samfya District.

The study area

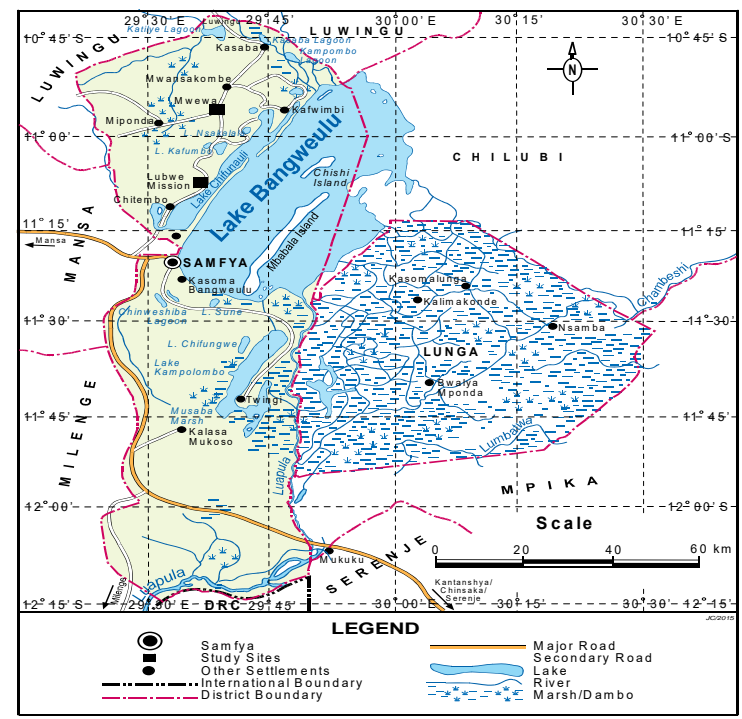

Figure 1. Location of samfya district

Source: Surveyor general (1979) and ministry of local government and housing (MLGH 2015).

The study area was Samfya District in the Luapula Province. This area was chosen other than Eastern Province even though they both lay in the zone 3 of malaria transmission because of its ecological nature that provided a geographical gradient in the spatio-temporal distribution of malaria. The demographic characteristics of the population were considered. These comprised of gender, age, income, education levels, occupation, roof construction materials, house exterior walls construction materials and sources of energy. These were considered to have contributed to the spatio-temporal distribution of malaria in Samfya District.

\section{Study design and sample size}

This was a transect study that was aimed at producing results that would show the geographical gradient of the spatio-temporal distribution of malaria in Samfya District. The employed both qualitative and quantitative techniques in order to ensure more accurate and stronger outcomes. Questionnaires (394 respondents), Interviews (11key informants), Focus Group Discussions (03), records and observations were used to collect the data. 


\section{Sampling procedure}

Random and non-random sampling procedures were used to select the respondents and the key informants respectively. The Yamane Formula was used to determine the sample size, the systematic sampling for the selection of the respondents to the sample, and the purposive sampling for the key informants.

\section{Results and discussion}

\section{Gender of the respondents}

The sample comprised a total of three hundred and ninety-four (394) respondents from the two sites, Lubwe and Mwewa. There were two hundred and one (201) and one hundred and ninety-three (193) for Lubwe and Mwewa respectively. These represented 51\% and 49\% of the whole sample population respectively. Of these respondents sixty point seven percent $(60.7 \%)$ were females while thirty-nine point three $(39.3 \%)$ were males. The trend in the gender classification conformed to that of the total population of Samfya whose $51 \%$ were females and $49 \%$ were males. The females were more than males, therefore, the sample was a representation of the whole population by gender.

The population was migratory and quite mobile. Some menfolk were camped at the Ifunge where they were herding their animals other than just fishing, while some had gone to the Copperbelt and Kasumbalesa in DRC to sell fish, agricultural produce (cassava and groundnuts) and brooms made from the Palm tree leaves. This therefore, left the women to head the households.

In this survey, gender was considered not just as a variable in the spatio-temporal sample representation, but had a relationship with malaria occurrence and infection. The women more especially the pregnant women were the most vulnerable to morbidity and mortality (Gabrielli et al. 2016). Pregnancy associated malaria had an increased risk to foetuses and its mothers through congenital malaria, increased malaria episodes, anaemia and non-malaria fever episodes (Moya-Alvarez, Abellan and Cot 2014). Women were more susceptible to malaria infection during pregnancy since the Pf, the most common parasite responsible for malaria, avoided the Spleen clearance through the expression of proteins that bound to the Chondroitin Sulphate A (CSA) in the placenta intervillous space (Fried and Duffy 1996). Consequently, the foetus was exposed to malaria in utero (Dellicour et al. 2010).

Some evidence of malaria in pregnancy (MIP) was congenial malaria. This was the presence of asexual Pf parasites in the cord blood or in the peripheral blood during the first week of infant life. This resulted from transplacental transmission of parasites just before or during delivery. The women FGDs also revealed that women were more vulnerable because:

They had 'thin' blood (umulopa awayanguka) due to menstrual flows they had every month. So when the blood flowed in the body to balance up the distribution, it equally spread the parasites throughout the body,

During pregnancy, the mother shared the blood with the baby and so the disease was passed on to the child and that,

The men were not subjected to these things and that was the reason why they rarely got malaria.

These responses were supported by outpatient hospital records that showed more women that suffered from malaria than the men. The common ailments for the men were sexually transmitted diseases and snake bites. The snake bites were more during the rainy season. This therefore suffices to say that the most critically hit by malaria were women and more so, the pregnant women and the children who got the malaria in utero. Mazigo et al. (2010) and Mwanje (2013) argued that pregnant women, infants/children and sick people were more vulnerable to disease and infection due to low levels of immunity and their bodies were more susceptible to malaria. The FGDs further revealed that the women were more susceptible to malaria because they compromised their immunity due to poor levels of nutrition. They served their husbands with the best food the household could afford thereby denying the 
children and themselves. This was done in conformity with cultural marriage and household teachings of reserving the best food for the husband (akatemba chupo). Culture therefore, indirectly contributed to disease occurrence in general and malaria in particular. This showed that gender played a role in the spatial-temporal distribution of malaria in Samfya District.

\section{Age of the respondents}

The ages of the respondents were slightly positively skewed but close to mean age since many were above the mean, therefore many respondents were older than 36.6 years. The measures of central tendency for the sample were: the mean age of the three hundred and seventy-one (371) respondents was 36.6 years, the median was 37.0 years and the mode was 38 years. The standard deviation was 12.3 years and all these averages lay within the first positive standard deviation which ranged from 36.6 years to 48.9 years. The modal age category was $35-44$ years with the highest percentage of thirty- three point four $(33.4 \%)$, while the aged of above sixty five years (65 years) were only three point two percent $(3.2 \%)$. There were differences in ages between Lubwe and Mwewa according to cohorts as illustrated in Figure 1 which provides the pictorial view of the distribution according to the study sites.

The overall result, however, showed asymptomatic significance. There was only a $0.8 \%$ variation in the figures. Mwewa had a much more elderly population than Lubwe. The reason for this was that Lubwe was a 'peri-urban' settlement with more government and nongovernment infrastructure that had created employment for the youthful. Mwewa was more of a rural agricultural settlement and a depository of those advanced in age. Table 1 illustrates the distribution of the sample population according to cohorts

Table1. Age distribution of the respondents

\begin{tabular}{|l|l|l|}
\hline Age categories & Frequency & Percent \\
\hline Between 15 and 24 years & 66 & 16.8 \\
\hline Between 25 and 34 years & 92 & 23.4 \\
\hline Between 35 and 44 years & 124 & 31.5 \\
\hline Between 45 and 54 years & 62 & 15.7 \\
\hline Between 55 and 64 years & 15 & 3.8 \\
\hline Above 65 years & 12 & 3.0 \\
\hline Total & 371 & 94.2 \\
\hline No age given & 23 & 5.8 \\
\hline Total & 394 & 100.0 \\
\hline
\end{tabular}

Source: Field data, 2015.

Five point eight percent $(5.8 \%)$ of the respondents did not indicate their age. This was a small percentage of the household heads that did not impact much on the results. Going by the trend that developed most respondents were not youths since they were 35 years and above. These constituted $59.8 \%$ of the whole sample as compared to $40.2 \%$ of the respondents who were below the age of 35 years. The study by Mazigo et al. (2010) revealed that the elderly population were affected by high poverty levels and were more vulnerable to malaria. The women focus group discussions that were done in this study also showed that the elderly in the communities were denied ITNs and this made them more vulnerable to malaria considering that their nutrition levels were also poor. 


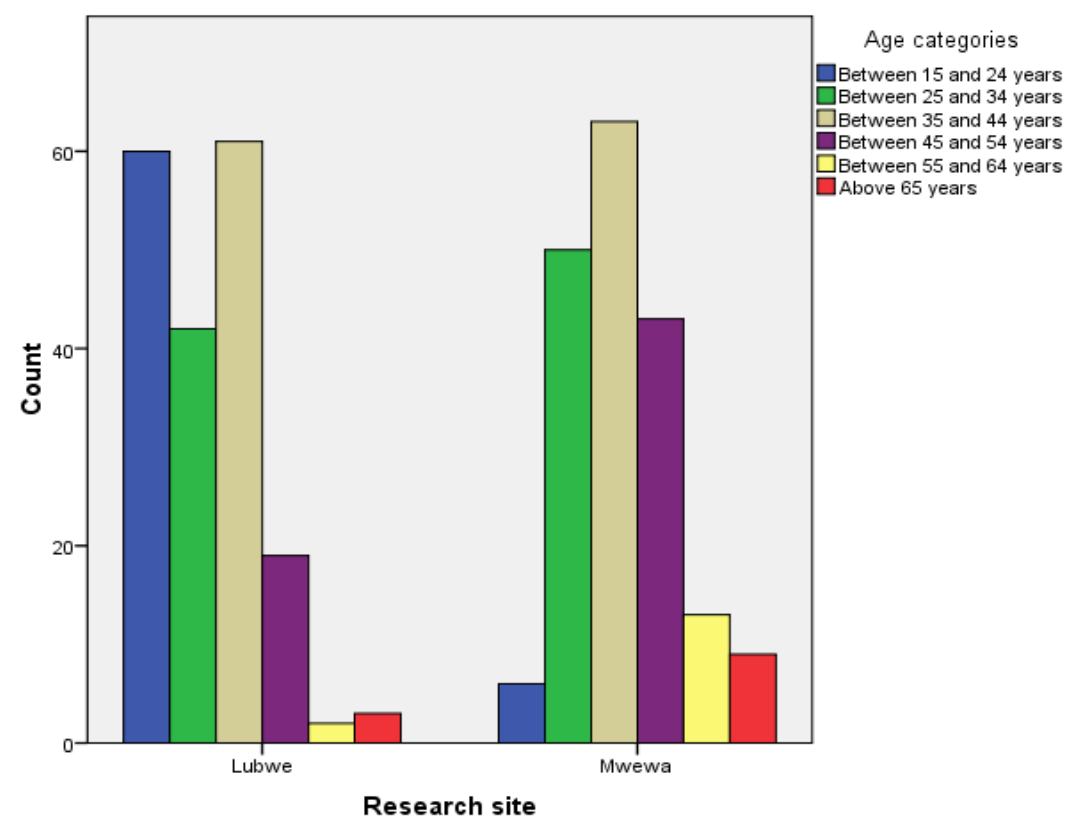

Figure 1. The distribution of respondents' ages according to sites

Source: Field data, 2015.

\section{Income for the respondents}

According to Table 2, there were three hundred and sixty-seven (367) respondents in the study (27 did not indicate their incomes) whose income ranged from one kwacha (K1) to twenty thousand kwacha (K20 000). Seventy-two point two percent $(72.2 \%)$ lay in the K1 to K700 per month bracket. This showed that the community was poor going by the income levels. The minimum income recommended by the Zambian government was seven hundred and fifty kwacha (K750) per month. Going by the United Nations poverty guidelines anyone that got less than one dollar per day, constituted poverty. Those in the first bracket, therefore, meant that the highest income was US\$ 0.22 per month which was spread amongst 265 respondents. This meant that each respondents earned US $\$ 1.90$ per month.

Eighty-eight point three percent (88.3\%) of the respondents were found in the income bracket ranging from one Kwacha (K1) to two thousand and one Kwacha (K2001) per month. Of this percentage, Lubwe accounted for 30.6\% while Mwewa had 47.7\%. Mwewa experienced more rural poverty than Lubwe. Only thirteen point three percent (13.3\%) received more than K2001 per month. Of these 7.6\% were from Lubwe and 5.7\% from Mwewa. Generally there was a significant difference according to the Chi-square (x2) result at $\mathrm{p}=0.05,95 \%$ level of significance with degrees of freedom (df) at six (6). The $\mathrm{X}^{2}$ crit $=12.592$ while $\mathrm{X}^{2}{ }_{\text {obs }}=15.768$. The calculated value was larger than the observed value. This meant that there was a significant difference in incomes between the two sites, Lubwe and Mwewa with the former having higher incomes.

Table 2. The respondents' total income per month

\begin{tabular}{|l|l|l|}
\hline & Frequency & Percent \\
\hline K1 to K700 per month & 265 & 67.3 \\
\hline K701 to K1, 400 per month & 37 & 9.4 \\
\hline K1, 401 to K2, 100 per month & 22 & 5.6 \\
\hline K2, 101 to K2, 800 per month & 11 & 2.8 \\
\hline K2, 801 to K3, 500 per month & 3 & .8 \\
\hline
\end{tabular}


Texila International Journal of Academic Research

Volume 4, Issue 1, Jun 2017

\begin{tabular}{|l|l|l|}
\hline K3, 501 to K4, 200 per month & 4 & 1.0 \\
\hline Above K4, 201 per month & 25 & 6.3 \\
\hline Total & 367 & 93.1 \\
\hline Did not indicate income & 27 & 6.9 \\
\hline Total & 394 & 100.0 \\
\hline
\end{tabular}

Source: Field data, 2015.

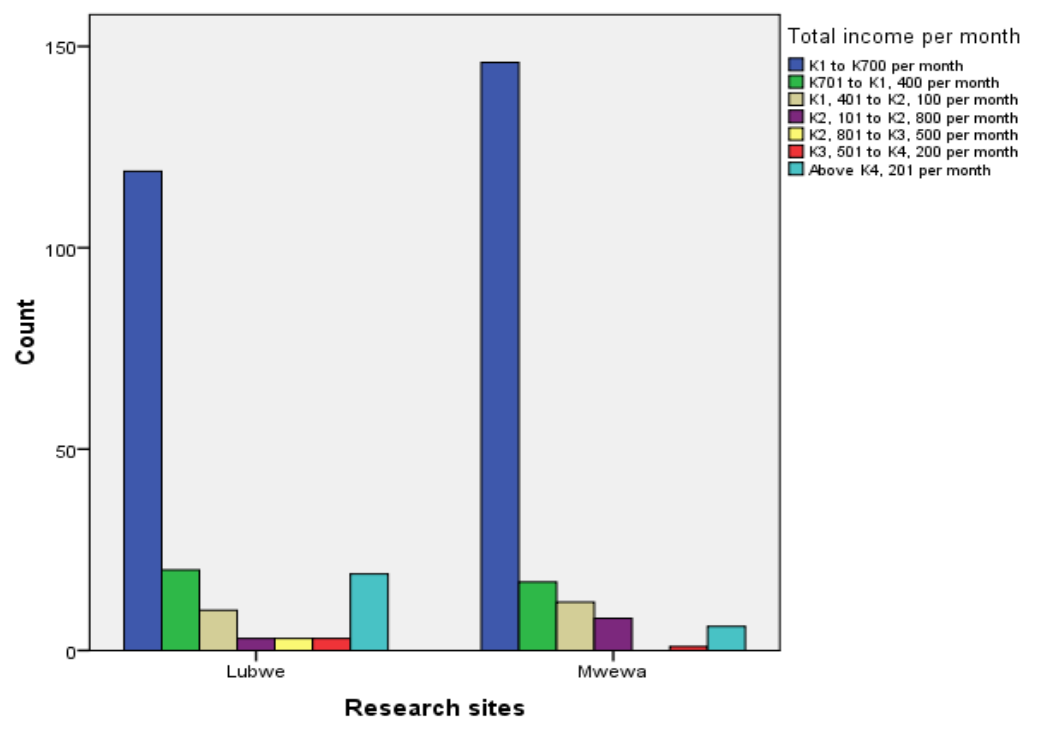

Figure 2. The respondents' income per month by research site

Source: Field data, 2015.

Figure 2 illustrates the distribution of the respondents' income categories. The incomes were spatially distributed in all income categories for Lubwe while Mwewa did not have any one who earned between K2801 to K3 500 per month. The low incomes and the elderly population contributed to poverty levels and ultimately to malaria occurrence and infection. These results were similar to the studies done Breman, Alilio and Mills (2004) and Sonko et al. (2014) which revealed that malaria was commonly associated with poverty and that malaria burden was highest in the poorest countries, particularly in sub-Saharan Africa. This was so because the area had little economic growth. The causal link between malaria and poverty ran in both directions.

Malaria

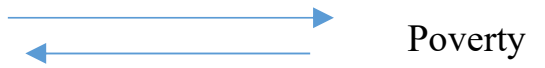

Breman et al. (2004) argued that the poor populations were at greatest risk; $58 \%$ of the cases occurred in the poorest $20 \%$ of the world's population and these patients received the worst care and had catastrophic economic consequences from their illness (Breman et al. 2004:1). This supported the assertion that malaria bred poverty and poverty later lead to disease. This therefore showed that the poor were more vulnerable to disease. The Samfya population was not of any exception as their incomes were quite low as illustrated in Figure 2.

\section{The respondents' education levels}

A total of eighty-seven point three percent $(87.3 \%)$ of the respondents had formal education while twelve point seven percent $(12.7 \%)$ had no formal education, as shown below: 
Source: Field data, 2015.

\begin{tabular}{|l|l|}
\hline Primary education & $36.5 \%$ \\
\hline Junior secondary education & $25.6 \%$ \\
\hline Senior secondary education & $20.1 \%$ \\
\hline Tertiary (certificate or diploma) & $5.1 \%$ \\
\hline
\end{tabular}

The education levels between the study sites varied from junior secondary to diploma. There were no respondents who had a university qualification in both study sites. Mwewa had a huge population of one hundred and thirty-five (135) respondents while Lubwe had one hundred and ten (110) who had education up to junior secondary school level (Grade 9). Those that had senior secondary and tertiary were sixty-seven (33.4\%) and thirty-two (16.6\%) for Lubwe and Mwewa respectively.

To confirm these differences, a Chi-square test was conducted. This test revealed that there was a significant difference in the levels of education between the two sites. The $X_{c a l}^{2}$ was 21.697 while the $X_{\text {crit }}^{2}$ was 9.80 . Since the observed value which was also the calculated X2 was higher than the critical value of $\mathrm{X} 2$ at four degrees of freedom $(\mathrm{df}=4)$, meant that Lubwe had a much more educated population than Mwewa Lubwe had diploma holders as the highest qualification while Mwewa did not have any

According to the Ministry of Health $(\mathrm{MoH}, 2013)$ education and literacy were among the major determinants of health and development and that it equipped people with knowledge and skills for problem solving, ability to access and understand information on health. These (education and literacy) further helped to provide a sense of control over life circumstances. Education had an impact on people's well-being. This view was supported by Sichande et al. (2014) who argued that there was a significant association between formal educational attainment and the individuals' health outcomes. These results were similar to the studies done much earlier by Tabthimer (2000) and, Mirowsky and Ross (2003). Furthermore, Feinstein's (1993) stated that there was an extensive negative association between education and disease in general, while Barret (1993) listed education as a factor responsible for health and unhealthiest. In short, education was important in one's wellbeing.

Generally, the education levels in Samfya were high in that eighty-seven point three percent $(87.3 \%)$ had formal education. Education was thought to have an impact on the level of knowledge, attitudes and perceptions on the spatio-temporal distribution and control of malaria in Samfya District. Further analysis showed that even though $87.3 \%$ had formal education, not many (62.2\% up to Junior secondary) were educated enough to the level of making rational decisions. This therefore, questioned their positive contributions towards malaria control.

\section{The respondents' occupation}

Figure 3 illustrates the various occupations the respondents were engaged in and these were synonymously used to mean livelihoods. 


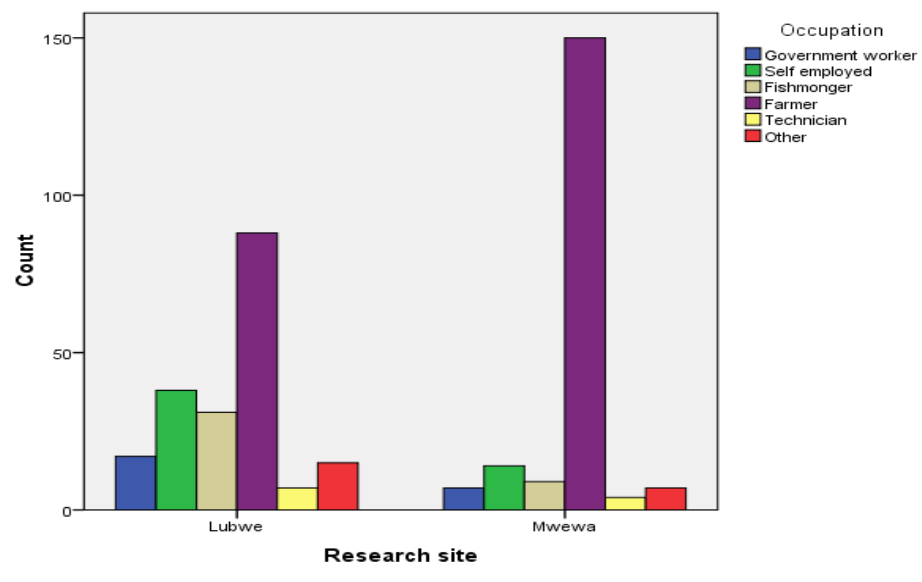

Figure 3. The respondents' occupations

Source: Field data, 2015.

The main occupation in the study area was farming which accounted for sixty- one point five percent $(61.5 \%)$ of the total population. Out of these seventy- eight point five percent (78.5\%) were in Mwewa while Lubwe had forty-four point nine percent (44.9\%) only. The farming was followed by self-employment for both Lubwe and Mwewa. The category of selfemployment constituted respondents that were traders (bars, shops, open air places or markets), transporters (either by wheelbarrows, bicycles, portage, vehicles or boats) or belonged to the hospitality industry (restaurant). This was then followed by fishing in both Lubwe and Mwewa. The least in the number of respondents were those with skills such as technicians who only accounted for three point six percent $(3.6 \%)$ and two point one percent (2.1\%) for Lubwe and Mwewa respectively. Those employed in government only comprised six point two percent $(6.2 \%)$ for the whole sample with the majority being found in Lubwe. There was an association between occupations, the levels of incomes and education attainment. The respondents' that were highly educated had occupations that were giving them high incomes as well, for example teachers and nurses. These variations impacted either negatively or positively on the malaria control strategies as understanding and perceptions were different.

\section{House construction materials}

The house construction materials determined the nature of the house. The house built out of mud and pole differed from one built with cement concrete blocks. These varied in outlook and size. The house materials were looked at also, as these were seen to contribute towards the spatio-temporal distribution of malaria in Samfya district. The study looked at the roof and exterior walls construction materials. Luapula in general and Samfya in particular had the same plan of houses whether the house was big or small. In very few places the plan had been modified to depict the household's socio-economic status. This scenario was common in Lubwe where income levels were much higher than in Mwewa. As earlier alluded to, Lubwe depicted a 'peri-urban' Ng'umbo land. Lubwe performed a number of functions through the accommodation of various social amenities such as schools, hospital, and cultural centre to mention a few. The Kwanga ceremony was held in Lubwe where cultural exchanges took place. The hospital had a large catchment population as some patients came from as far as Chilubi Island in Northern Province. These travelled using speed boats that docked at a harbour by the Chifunabuli shore. Due to the socio- spatial extent, there were high levels of socialization and different diffusion processes occurred. This however, did not impact on the historical appearance of the houses. Plates 1 and 2 show the two types of houses that were found in the study sites. 


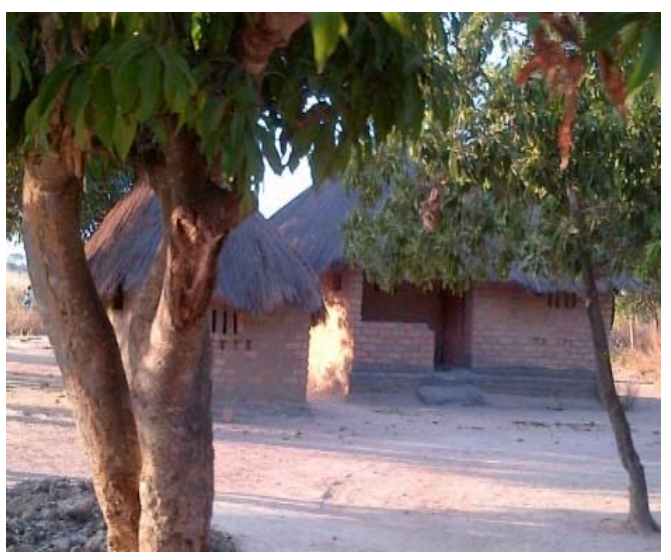

Plate 1: An indigenous house type

Source: Field data, 2015.

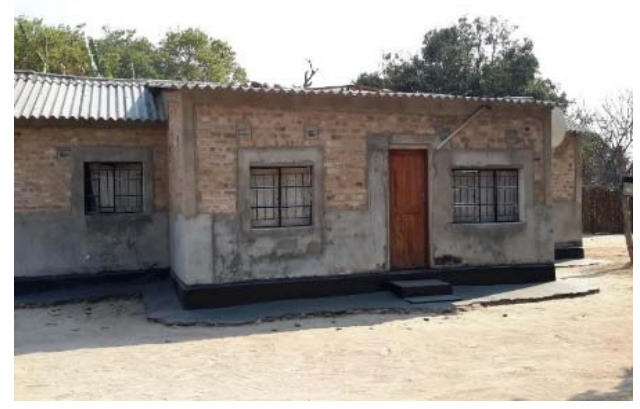

Plate 2. A modern house type

Source: Field data, 2015.

Sonko et al. (2014) argued that there was an association between malaria occurrence and housing: for instance, through improved housing malaria was eliminated in the United States of America, Italy, Greece and Spain. Doors and windows were screened to reduce contacts between people and mosquitoes. In Gambia, a randomized controlled trial of full screening of doors and window s, and closing of eaves showed a fifty percent (50\%) decline in the risk of anaemia related malaria among children (Kirby et al. 2009:998). This trial showed that improvements in housing quality could greatly reduce malaria transmission and incidence. This view was similar to what Snow and Gilles (2002), found out too, in their study.

Rocci (2012) argued that improvements in the living conditions of populations in endemic communities had an impact on malaria burden. The study revealed that housing construction materials for the walls, floor, roof and window were strongly associated with the risk of infection in most age groups. Although in the general population this was true for poor wall housing materials.

\section{Roof construction materials}

There were three types of roof construction materials and these were straw/thatch, iron/asbestos sheets and tiles. Sixty point nine percent $(60.9 \%)$ of the roofing materials was straw/grass, followed by iron/Asbestos sheets with thirty-three point five percent $(33.5 \%)$ and tiles with only two point three percent $(2.3 \%)$ as Figure 4 illustrates. Three point three percent $(3.3 \%)$ did not indicate the roof materials. 


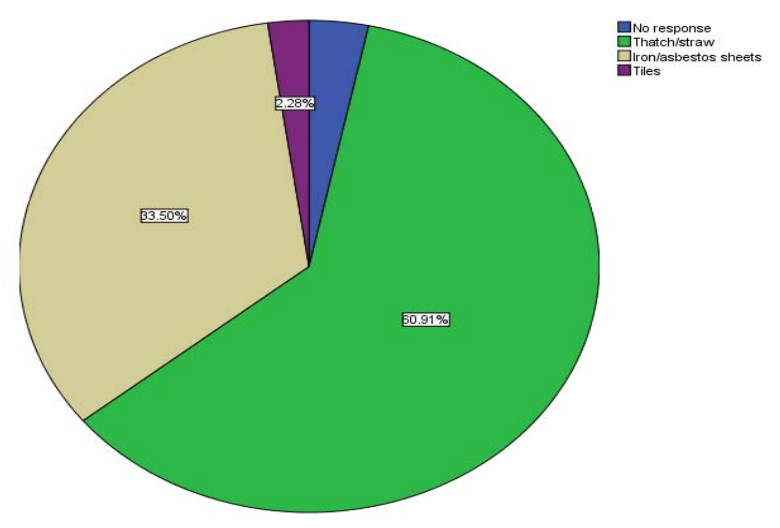

Figure 4. The type of roof construction materials

Source: Field data, 2015.

The chi-square $\left(\mathrm{X}^{2}\right)$ test revealed that the $X_{\text {cal }}^{2}$ which was 16.0 was larger than the $\mathrm{X}^{2}$ crit of 4.41. This therefore, showed a significant difference in the usage of the roofing materials at $\mathrm{df}$ $=3$. The trend in the use of roofing materials for the whole sample was similar to that of Lubwe and Mwewa.

These roof construction materials were related to the use of interventions more especially the ITNs. Hanging of ITNs was more of a challenge in a thatched house than was in a house roofed with Iron/Asbestos sheets. Other factors such as the space that was left between the exterior walls and the roof (thatch) was equally a challenge as this permitted entrance of more mosquitoes. The thatched roof concealed the presence of mosquitoes due to the colour and roughness of grass.

There was more vulnerability to malaria in a thatched house than in a house roofed with Iron/Asbestos sheets or tiles. The beams that were regularly placed were used to hang the ITNs. This factor attributed to the annual occurrence of malaria in Samfya district. Earlier studies that were done in Mozambique, Eritrea and the Lao People's Democratic Republic showed that living in houses with grass roof was associated with higher odds of malaria infection and was reason enough for Samfya's endemicity.

\section{House exterior walls construction materials}

There were different exterior wall construction materials in the study sites and these were mud and poles, unburnt bricks, burnt bricks, timber straw/grass and cement blocks. Sixty-one point two percent $(61.2 \%)$ of the respondents had the exterior walls of their houses made from burnt bricks, followed by the usage of cement blocks (13.7\%), unburnt bricks (10.9\%), mud and pole, and timber had five point three percent (5.3\%) each. Straw/grass had only zero point three percent $(0.3 \%)$. Figure 5 shows the distribution of house exterior wall construction materials in the study area.

The disparities occurred in the type of exterior wall construction materials and not between the study sites. The trend in the utilization between the sites was similar.

There were sixty-two point seven percent (62.7\%) of the households in Mwewa which used burnt bricks while in Lubwe only fifty-nine point seven percent (59.7\%). Cement blocks were used by sixteen point one percent $(16.1 \%)$ and eleven point four percent $(11.4 \%)$ for Mwewa and Lubwe respectively. Generally Mwewa had more households whose houses were constructed with better house building materials than Lubwe. Some houses were constructed from timber, grass and mud and pole. Such houses were more in Lubwe. 


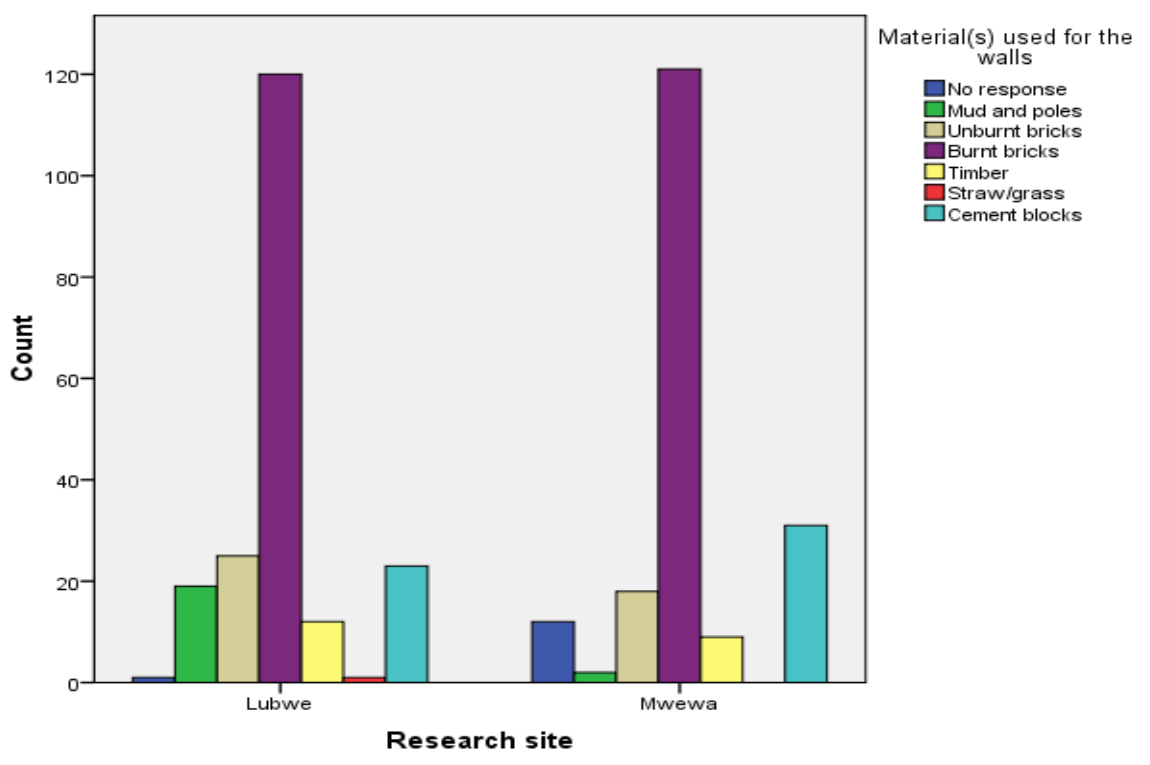

Figure 5. House exterior wall construction materials according to the sites.

Source: Field data, 2015.

Rocci (2012) revealed that houses constructed with bamboo walls, poorly fitted windows and doors often inhabited by people from the low socio-economic status were associated with mosquitoes' house entry. Living in houses with no screens or windows was likely to increase individual contact with the mosquito vector. Similarly so, even where mud was used as material, it was equally associated with high prevalence of malaria. In this study a total of sixteen point five percent (16.5\%) houses had their exterior walls constructed out of timber, grass and mud and pole. These apparently increased the vulnerability of the occupants to malaria infection and also put their community at a higher risk.

\section{The respondents' sources of energy}

The sources of energy were also considered in this study as some sources were said to impact on the use of malaria intervention strategies such as the ITNs. There were five sources of energy that were used in this study area namely: hydroelectricity, firewood, charcoal, crop residue and a combination of firewood and charcoal as indicated in Table 3.

Table 3. The distribution of the respondents' sources of energy

\begin{tabular}{|l|l|l|l|}
\hline Sources of energy & Whole sample (\%) & Lubwe (\%) & Mwewa (\%) \\
\hline Hydroelectricity & 9.4 & 15.4 & 3.1 \\
\hline Firewood & 50.5 & 37.3 & 64.2 \\
\hline Charcoal & 36.3 & 41.3 & 31.1 \\
\hline Crop residue & 3.0 & 4.5 & 1.6 \\
\hline Firewood and charcoal & 0.8 & 1.5 & 0.0 \\
\hline Total & 100.0 & 100.0 & 100.0 \\
\hline
\end{tabular}

Source: Field data, 2015.

From Table 3, fifty point five percent (50.5\%) of the respondents used firewood as their source of energy, while thirty-six point three percent (36.3\%) used charcoal, nine point four percent $(9.4 \%)$ used electricity, crop residue and, firewood and charcoal accounted for a total of three point eight percent (3.8\%) of the respondents. The most common energy source for Lubwe was charcoal which accounted for forty-one point three percent $(41.3 \%)$, while that of Mwewa was firewood that was used by sixty-four point two percent $(64.2 \%)$ of the respondents. Both communities however, used charcoal and firewood more than any other source of energy. 
The results on the sources of energy showed a double variation. The first one was within the energy sources and the second was between the study sites. This was confirmed by the Chi-square (X2) test that was carried out whose calculated value was $X_{\text {cal }}^{2}=41.535$ and the critical value at four degrees of freedom $(4 \mathrm{df})$ was $X_{\text {crit }}^{2}=1.47$. This therefore entailed that there was a significant difference in the sources and the utilization of energy in the sample area and also between the sites.

The sources of energy used was related to the location of the house. The implication of the source of energy on malaria control was that, those that used firewood within the premises where the household members slept, had their bed nets polluted with smoke. This meant that the bed nets were subjected to more washings than what was recommended thereby compromising the efficacy and efficiency of the insecticide and the bed net respectively. The men's FGD revealed that, due to smoke pollution in the houses, the nets were subjected to frequent washes. This reduced the impregnation of the insecticide so was the efficacy. The households did not have the capacity to retreat the nets. Additionally, some nets had developed holes that could no longer be stitched. This therefore, reduced the effectiveness of the net as a vector preventive measure.

\section{The Spatio-temporal distribution of malaria in samfya}

Malaria in Samfya was spatially distributed. All places did have malaria occurrence and was a major cause of morbidity in the population more especially the children and pregnant women. Luapula province was in zone 3 of the malaria transmission where the infection rate was more than twenty percent $(>20 \%)$ during the hot rainy season. Samfya district which is found in Luapula also had a high malaria transmission in the rainy season. Malaria incidents occurred throughout the year as illustrated in Figure 6, and this meant that malaria in Samfya was endemic.

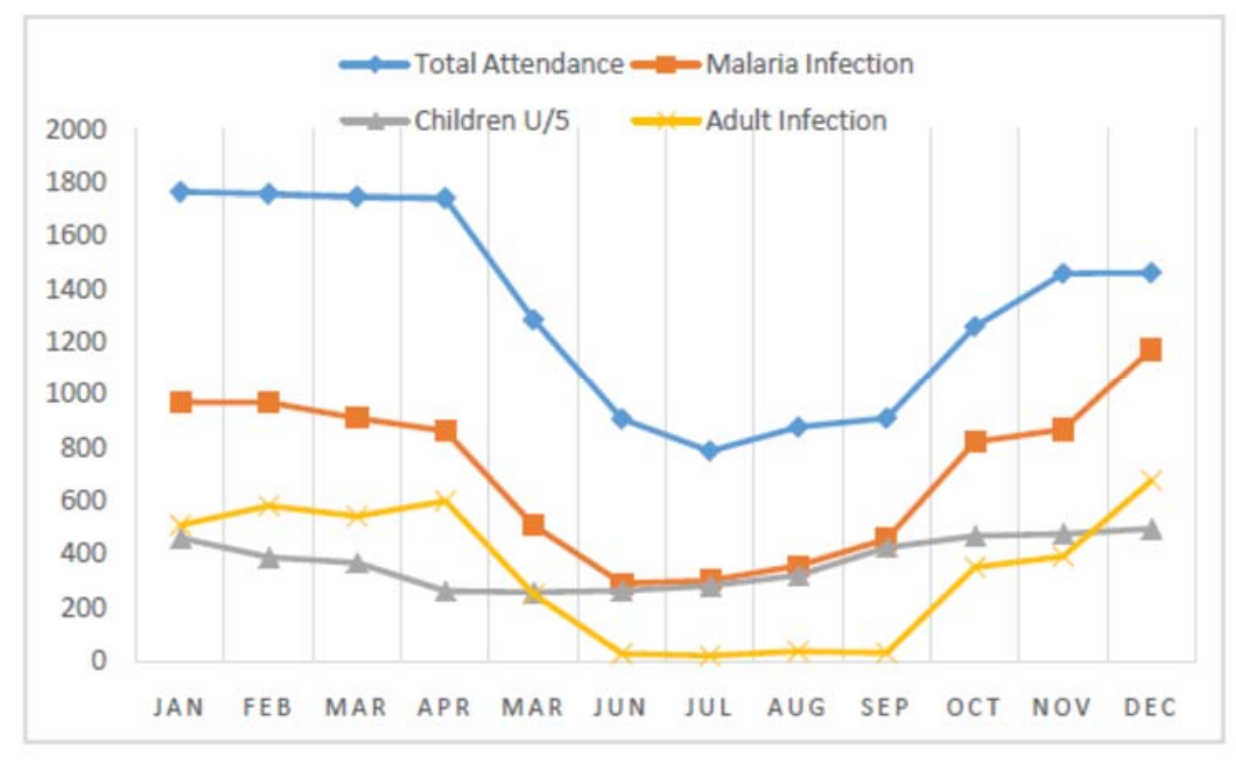

Figure 6. The temporal distribution of malaria in samfya district

Source: Field data, 2015.

The figure shows the malaria incidence levels in Samfya district from January to December. The highest figures occurred during the rainy season as this period was also characterized with high temperatures values from $260 \mathrm{C}$ to $300 \mathrm{C}$ (SDC, 2011) that favoured the breeding of mosquitoes. There was also a lot of stagnant rainy water that provided for ideal breeding conditions for mosquitoes. The stagnant water collected in ditches that were created as a result of quarrying for building materials. The sand and silt were quarried along the lake shores, lagoons and river banks. The Musaila-Lubwe road which was constructed on an embankment between Mashitolo and Lubwe was heavily quarried on the sides. This had 
made the road to weaken on the sides and more so it was exposed to erosion that occurred during the heavy rain downpours. The lagoons which lay between Lubwe and Mwewa, equally had their shores quarried. While on the outskirts of Mwewa towards Miponda the stream banks were quarried. These materials were used in various forms of construction. The other source for quarry construction building materials were anthills whose soil was used for moulding bricks used in the exterior walls construction materials. The construction materials for the houses and other structures also contributed to the occurrence of malaria in Samfya. This therefore, put Samfya as a malaria endemic place.

Breman (2001) argued that a substantial percentage of the population in endemic areas had parastaemia any one time and children less than five years $(<5$ years) had four to nine $(4-9)$ or more febrile episodes each year. This condition was similar in Samfya district. Other than just the type of houses, the population was accustomed to spending evenings outside, the time when most mosquitoes fed. According to the results of the survey, seventy-four point nine percent $(74.9 \%)$ knew that mosquitoes fed at night while twenty-one point one percent (21.1\%) stated that the mosquitoes fed both day and night, and the remaining number of respondents $(2.8 \%)$ said that the mosquitoes fed during day time. The main response did not correspond to the respondents' attitude of spending a greater part of the evenings outdoors. This therefore, made them more vulnerable to mosquito bites.

There was more mosquito nuisance outdoors than indoors due to some interventions such as the use of mosquito repellents (sprays, coils and leaves). These reduced the mosquito populations inside the houses. This therefore enhanced the occurrence of malaria everywhere in the district and throughout the year.

The graphs in Figure 6 show similar trends in all the three categories of total hospital attendance, total malaria infections and the infected under five years children. The graphs presented show the figures of those that visited the health centre per month and throughout the year. Those that had tested positive for parastemia had the numbers for $U / 5$ years children extracted from the whole group of infected people. The figures for the infected under five years children from July to September exceeded those of above the age of five years (>5years). This indicated that there were more children $\mathrm{U} / 5$ years that were sick in the population in Samfya District.

\section{The total hospital attendance}

According to the findings, the total hospital attendance was much higher from January to April where the figures were above 1700 patients per month. Thereafter, the numbers began to drop to about 800 in July, then again started to increase and by December the figure had risen to 1461 .

\section{Total malaria infection}

Malaria infection followed a similar trend to that of total hospital attendance. Out of the 1764 patients in January, 970 were diagnosed with malaria representing a $55 \%$ of the total hospital attendance. This was critical where more than half of that population had malaria. The lowest malaria infection was in June where only $32 \%$ of the total hospital attendance were infected. This therefore, denoted that when moisture and temperature levels rose, so were the infection rates. When these reduced, similarly the infection rates lowered. This therefore, showed some correlation between the collaborative climatic pattern and malaria infection rates.

\section{Infected children under the age of five years}

Forty eight percent (48\%) of the children under five years were infected out of the total of 970 for the month of January. In June even though the figure was small (290) for total malaria infection, 263 were children under the age of five years. This was a ninety point seven percent $(90.7 \%)$ representation of the total infected patients. The hospital case reporting was low as the elderly resorted to other treatment seeking behaviours. 
Texila International Journal of Academic Research

Volume 4, Issue 1, Jun 2017

\section{Conclusion}

Malaria in Samfya was endemic and spatially distributed in the entire district with temporal variations within the year according to the climatic pattern as indicated in Figure 6. The cold season had the lowest infection rates while the rainy season had the highest. The gender, age, income, education levels, occupation, roof construction materials, house exterior walls construction materials and sources of energy had a bearing towards the persistence of malaria in Samfya district.

\section{Acknowledgements}

My sincere gratitude to the respondents and the key informants whom without their cooperation this work would have not been possible.

\section{References}

[1]. Barret L (1993). 'The phases and focus of empathy'. British Journal of Medical Psychology. 66: $3-14$

[2]. Breman J G (2001). 'The ears of the hippopotamus manifestations, determinants and estimates of malaria burden'. American Journal of Tropical Medicine and Hygiene. 64: 1-11.

[3]. Breman J G, Alilio M S and Mills A (2004). Conquering the intolerable burden of malaria: what's new, what's needed: a summary'? Journal of tropical Medicine and Hygiene. 71 (suppl 2): 1-15.

[4]. Dellicour S, Tatem A J, Guerra C A, Snow R W and ter Kuile F O (2010). Quantifying the number of pregnancies at risk of malaria in 2007: a demographic study. PLoS Med. 7: e 1000221

[5]. Feinstein J (1993).'Elderly health, housing and morbidity', Working Paper 4572: National Bureau of Economic Research in Baker et al. (2011), Population and Development Review. 37. 2: 307-332.

[6]. Fried M and Duffy P E (1996). 'Adherence of Pf to chondroitin sulphate A in the human placenta'. Science. 272: 1502-1504.

[7]. Gabrielli S, Bellina L, Milardi G L, Katende B K, Totino V et al. (2016). 'Malaria in children of Tshimbulu (Western Kasai, Democratic Republic of the Congo): epidemiological data and accuracy of diagnostic assays applied in a limited resource setting'. Malaria Journal. 15: 81.

[8]. Kirby M J, Ameh D, Bottomley C, Green C, Jawara M, Milligan P J, Snell P C, Conway D J and Lindsay S W (2009). 'Effect of two different house screening interventions on exposure to malaria vectors and on anaemia in children in the Gambia: a randomized controlled trial'. Lancet. 374: 9981009.

[9]. Mazigo, H.D., Obaasy, E., Mauka, W., Manyiri, P., Zinga, M. and Kweka, E. J. (2010). "Knowledge, attitudes and practices about malaria and its control in rural Northwest Moya-Alarez V, Abellana R and Cot M (2014). 'Pregnancy-associated malaria and malaria in infants: an old problem with present consequences'. Malaria Journal. 13: 271.

[10]. Ministry of Health (MoH 2014). Malaria and Vector-borne diseases control strategy 2015-2019 in Eritrea: The Malaria National Programme. Eritrea: MoH (MoH 2013). National Health Policy: A Nation of Healthy and Productive People. Lusaka: MoH. Ministry of Local Government and Housing (MLGH 2015). Topographical Map Sheets 1029 D and 1129 B- an upgrade. Lusaka: MLGH.

[11]. Mwanje L F (2013). 'Knowledge, attitudes and practices on malaria prevention and control in Uganda: A case study of Nsaabwa village, Mukono District'. Post-Doctoral Report. Kampala: Gulu University.

[12]. Nzobo B J, Ngasala B E and Kihamia C M (2015). 'Prevalence of asymptomatic malaria control measures among primary school children in Morogoro Municipality, Tanzania'. Malaria Journal. 14: 491.

[13]. Patney S (2013). Community Health Nursing. New Delhi: Satin Kumar Jain.

[14]. Rocci F (2012). 'Social implications of malaria and their relationships with poverty'. Mediterranean Journal of Haematology and Infectious Diseases. 4: e 2012048.

[15]. Samfya District Council (SDC 2011). Samfya District Situation Analysis. Samfya: SDC.

[16]. Sichande M, Michelo C, Halwindi H and Miller J (2014). 'Education attainment of the head of households associated with insecticide treated net utilization among five to nineteen year old individuals: evidence from the malaria indicator survey 2010 in Zambia'. Malaria Journal. 13: 378. 
[17]. Snow R W and Gilles H M (2002). 'The Epidemiology of Malaria' in Warell D A and Gilles H M (ed). Essential Malariology. Pp. 85-106.

[18]. Snow R W and Omumbo J A (2006) "Malaria", Disease and Mortality in Sub-Saharan Africa. Washing DC: World Bank.

[19]. Sonko S T, Jaiteh M, Jafali J, Lamin B S, D’Alessandro U, Camara A and Komma-Bah M (2014). 'Does socio-economic status explain the differentials in malaria parasite prevalence? Evidence from the Gambia'. Malaria Journal. 13: 449. Pp 1-12.

[20]. Surveyor General (1979). Topographical Map Sheets 1029 D and 1129 B. Lusaka: Ministry of Lands.

[21]. Tabthimer G (2000). ). 'Malaria and Environment in Ethiopia: A case study of Wonji Shoa sugar estate'. Masters of Philosophy in Social Change. Norway: Norwegian University of Science [22]. World Health Organization (2014). World Malaria Report-2014. Geneva: WHO. 